\title{
КОНЦЕПТУАЛЬНЫЕ ПОЛОЖЕНИЯ МЕНЕДЖМЕНТА СБАЛАНСИРОВАННОСТИ РАЗВИТИЯ ПРОМЫШЛЕННОГО КОМПЛЕКСА
}

Рассмотрены особенности современного аспекта проблемы менеджсиента сбалансированности развития промыииленного комплекса, связанные с необходимостью перехода к новому технологическому укладу. Рассмотрены различные аспекты суцности категории сбалансированности, которые связаны с балансированием потоков различного вида: материально-вецественных, сочиально-трудовьх, информационньх и других, которье требуется представить также в стоимостном выражении и обеспечить их финансовое равновесие. В результате интеграции различных методологических подходов к оценке сбалансированности предложена дуальная концепчия ее оценки. На этой основе проведена оченка сбалансированности по федеральным округам. Вылявлено, что дисбалансы становятся источником резкого снижения эффективности функционирования компаний. Концептуально механизм менеджсмена сбалансированности развития территориальных промыииленных комплексов должен строиться, опираясь на систему предложенных в работе принципв, объединяя возможности оперативного управления и стратегического менеджмента. Менеджмент сбалансированности развития предприятий индустрии предполагает его систематическое обновление, включая разработку инновачионных подходов и современных инструментов.

Ключевые слова: оценка сбалансированности, менеджсиет сбалансированности развития, промыпиленный комплекс, стратегический менеджмент, принципы менеджмента сбалансированности.

\section{Pavel Timoshenko \\ CONCEPTUAL PROVISIONS OF THE BALANCED MANAGEMENT DEVELOPMENT INDUSTRIAL COMPLEX}

The features of the modern aspect of the management problem of the balance of the development of the industrial complex, associated with the need to move to a new technological order are considered. Various aspects of the essence of the category of balance are considered, which is associated with balancing flows of various types: material, social, labor, information, and others, which are also required to be presented in monetary terms and ensure their financial balance. As a result of the integration of various methodological approaches to the assessment of balance, a dual concept of its assessment is proposed. On this basis, an assessment of the balance in federal districts has been carried out. It is revealed that imbalances become a source of a sharp decline in the efficiency of the functioning of companies. Conceptually, the management mechanism for balancing the development of territorial industrial complexes should be built on the basis of the system of principles proposed in the work, combining the possibilities of operational management and strategic management. Managing a balanced development of enterprises in the industry implies its systematic updating, including the development of innovative approaches and modern tools.

Key words: balance balance assessment, development balance management, industrial complex, strategic management, balance management principles.

Bведение / Introduction. Особенности нового современного аспекта проблемы менеджмента сбалансированности развития промышленного комплекса состоит в необходимости перехода к новому технологическому укладу и значимости роста на этой основе масштабов экономики и производственных взаимосвязей. Он состоит в обеспечении сбалансированности динамики и пропорций развития промышленного комплекса как на макро-, так и на микроэкономическом уровне с учетом динамично изменяюшейся структуры хозяйства. 
Mameриалы и методы / Materials and methods. В современной экономической терминологии используются несколько понятий, характеризующих состояние социально-экономической системы, близкое к сбалансированному: «равновесие, уравновешенность», «сбалансированность», «пропорциональность», «гармоничность», «(согласованность», «стабильность», «устойчивость».

Это свидетельствует о том, что категория «сбалансированность» не имеет признанного однозначного толкования.

Исследуя различные аспекты сущности категории сбалансированности, которое является целевой функцией менеджмента, можно заключить, что в наиболее общем понимании сбалансированность определяют как баланс (соответствие, согласование) элементного состава социально-экономических систем и процессов, протекающих в них (поступления доходов и расходования полученных средств, активов и пассивов, необходимых и имеющихся ресурсов, объемов спроса и предложения, сроков выполнения требуемых и возможных заказов и др.), которые рассматриваются в структурном, процессном, качественном и количественном, натурально-вещественном и финансовом и других аспектах.

Методику оценки сбалансированности необходимо строить на базе балансирования потоков различного вида: материально-вещественных, социально-трудовых, информационных и других, которые требуется представить также в стоимостном выражении и обеспечить их финансовое равновесие. Указанные балансовые соотношения получают свое выражение в промышленной компании в виде соответствия производства объемов изделий и рыночного спроса на них, а также как баланс доходных источников и расходов фирмы с учетом их динамики, их объемов во времени. В территориальном аспекте баланс экономических и финансовых потоков отражается в виде соответствия платежеспособного спроса и предложения различных товаров и услуг на региональном рынке, а также в сбалансированности доходов и расходов (отсутствии дефицитов) государственного и муниципальных бюджетов, что считается важнейшей целью управления государством и его территориальными образованиями.

Результаты и обсужсдение / Results and discussion. Исследование показало, что все формы сбалансированности взаимосвязаны, хотя и обладают некоторой самостоятельностью. При этом можно наблюдать, что за счет нарушения баланса в одной части системы или процесса достигается сбалансированность в другой: к примеру, получение отрицательного результата в балансе доходов и расходов может дать возможность закупить требуемые материальные запасы, за счет превышения импорта над экспортом закупаются новые образцы техники и технологии и т. п.

В ходе инновационного развития индустриальных компаний осуществляется циклическое и эпизодическое формирование и разрушение отношений и взаимодействий между фирмами во внешнем и внутреннем окружении (между подразделениями компаний) со следующим за этим переструктурированием взаимосвязей с целью их воспроизведства на ином, более высоком и / или адекватном произошедшим изменениям уровне на основе формирования динамического соответствия отношений со стейкхолдерами [1].

В связи с этим менеджмент сбалансированности развития предприятий индустрии предполагает его систематическое обновление, включая разработку инновационных подходов и современных инструментов. В составе наиболее применяемых методов менеджмента в настоящее время целесообразно отметить: аналитико-диагностические, оценочно-параметрические, прогнозно-индикативные; при этом в совокупности признанных инструментов выделяют: нормативно-регламентирующие, планово-аналитические, мотивационные и стимулирующие.

Следует отметить, что проблемой менеджмента сбалансированности развития индустриальных комплексов является слабая проработанность критериев сбалансированности / гармоничности в трудах разных авторов. Это ставит препятствие в обеспечении сопоставимости промышленных компаний с различными уровнями развития сбалансированности, а тем более отсутствуют варианты оценивания сбалансированности менеджмента развития региональных промышленных комплексов. 
По нашему мнению, методики такой оценки целесообразно сформировать на основе приемлемых методов достижения баланса, и использовать расчеты таких показателей:

1) уровня соответствия критерию сбалансированности;

2) уровня соблюдения ограничений, нормативов и пропорций;

3) уровня осушествления требуемых функций и действий;

4) величины корреляционной связи темпов изменений наиболее важных параметров и динамики рангов их приоритетности [2].

$\mathrm{C}$ позиций менеджмента сбалансированности важно сопоставление динамики изменений промышленных комплексов в разных регионах, поскольку сильное воздействие оказывает специфика действий территориальной власти и региональные особенности исторического развития индустриальных комплексов $[3,4]$.

В результате интеграции различных методологических подходов к оценке сбалансированности (процессного, целевого, стейкхолдерского, финансового, рыночного и др.), предложена дуальная концепция ее оценки: выделены два аспекта сбалансированности - функционирование и развитие, и две ее разновидности - внешняя и внутренняя, а также большое число ее форм, которые отличаются между собой в отношении оценки сбалансированности.

Нами предложено для обеспечения идентичности оценивания сбалансированности функционирования промышленного комплекса с точки зрения внешнего и внутреннего ее отражения использовать следующий перечень ее форм: финансовая; экономическая; материальная; целевая / технико-технологическая; инновационная; трудовая; социальная; экологическая.

Оценивание сбалансированности развития индустриального комплекса рекомендуется выполнять по уровню согласования изменений первичных параметров, которые объьединены в пять групп:

1) финансово-экономические результаты;

2) нефинансовые производственные результаты;

3) затраты;

4) социальные результаты и затраты;

5) потери, негативные результаты.

Для выполнения сопоставимого анализа показатели, использованные для оценки сбалансированного развития промышленности России, применены и для оценки ее региональной специфики.

В целом, интегрируя полученные данные, можно сделать выводы, отразив их в таблице.

Общая характеристика уровня и динамики сбалансированности по федеральным округам РФ в 2011-2015 гг.

\begin{tabular}{|c|c|c|}
\hline $\begin{array}{l}\text { Уровень и динамика } \\
\text { сбалансированности }\end{array}$ & Округ & Характеристика уровня и динамики сбаллансированности \\
\hline \multirow{3}{*}{$\begin{array}{l}\text { Высокий, относительно } \\
\text { устойчивый }\end{array}$} & ЦФО & Устойчиво высокий уровень, но резкое падение в 2015 г. \\
\hline & ДВФО & $\begin{array}{l}\text { Высокий уровень, но резкое падение в } 2013 \text { г. с восстановлением в } \\
2015 \text { г. }\end{array}$ \\
\hline & СЗФО & Высокий уровень - 2011-2012 гг. \\
\hline $\begin{array}{l}\text { Высокий, } \\
\text { неустойчивый }\end{array}$ & УФО & $\begin{array}{l}\text { В период наблюдения - } 5 \text { лет - имелось два резких падения сбаланси- } \\
\text { рованности в } 2013 \text { и } 2015 \text { годах }\end{array}$ \\
\hline \multirow{3}{*}{ Средний, устойчивый } & ПФО & \multirow{3}{*}{$\begin{array}{l}\text { Уровень в основном средний - } 0,2-0,15 \text {; колебания небольшие, нерез- } \\
\text { кие. Немного выше уровень у ПФО. Его можно в начале периода отне- } \\
\text { сти к регионам с относительно высоким уровнем сбалансированности. }\end{array}$} \\
\hline & ЮФО & \\
\hline & СФО & \\
\hline \multirow[t]{2}{*}{ Низкий } & СКФО & $\begin{array}{l}\text { Низкий уровень в течение всего периода наблюдения, кроме } 2015 \text { г., } \\
\text { где сбалансированность обеспечена равномерным снижением всех } \\
\text { показателей региона. }\end{array}$ \\
\hline & $\mathrm{C} 3 Ф \mathrm{O}$ & Низкий уровень - в 2013-2015 гг. \\
\hline
\end{tabular}


При оценке сбалансированности было выявлено, что все федеральные округа (за исключением СКФО) в течение всего анализируемого периода демонстрировали стабильно высокий уровень роста такого показателя, как выпуск инновационной продукции (индекс роста объема инновационных промышленных товаров), что свидетельствует о приоритетности этого показателя и должно быть отражено в системе приоритетов. Кроме этого, серьезным, не зависящим от регионов РФ фактором стали санкционные ограничения по экспорту и импорту товаров, что привело к разработке и реализации в промышленной отрасли стратегии импортозамещения и «ухода» от приоритетности «работы на зарубежных рынках». Это также предопределило изменение баланса ценностей, и на данный момент времени нельзя не учесть изменения в этой области.

Необходимость менеджмента сбалансированности развития промышленных комплексов региона связана тем, что дисбалансы становятся источником резкого снижения эффективности функционирования компаний, приводят к кризисам, создают угрозы экономической безопасности страны. Как следствие, механизмы менеджмента сбалансированности развития территориальных промышленных комплексов, по нашему мнению, должны способствовать предотвращению указанных негативных результатов. Основу для их создания и совершенствования составляют следующие утверждения $[2,5,6]$ :

1) исходными предпосылками для разработки моделей оценки являются представления о главных причинах несбалансированности в динамике индустриальных комплексов и обусловленных ими угроз экономическому развитию отдельных территорий и страны в целом;

2) информационную основу оценки сбалансированности целесообразно сформировать по итогам проведения мониторинга состояния индустрии на той или иной территории или в стране в целом, который позволит своевременно установить проблемы ее развития, диагностировать возможные угрозы в экономике промышленных комплексов и спрогнозировать их динамику;

3) механизм менеджмента сбалансированности развития промышленного комплекса объединяет в комплекс иерархические уровни управления экономикой соответствующей территории. Определенной совокупностью специфических прав, полномочий и ответственности в указанном механизме должны обладать как промышленные фирмы, так и муниципальные и государственные органы власти местного, регионального и федерального уровней (особенно, если это касается национальных интересов);

4) представленные группы субъектов управления в механизме менеджмента сбалансированности развития промышленных комплексов разного уровня обладают собстввенными ресурсами и возможностями, функционирование этих субъектов определяется их специфическими интересами, стратегиями и целями, которые иногда не совпадают и приводят к разбалансированности развития индустриальных комплексов, причем как в долгосрочном, так и в краткосрочном периоде;

5) для обеспечения согласованности целей и стратегий стейкхолдеров в механизме менеджмента сбалансированности развития промышленных комплексов необходимы инициирующие действия органов власти с применением различных прямых и косвенных методов регулирования поведения стейкхолдеров. К таким методам относят нормативно-правовые меры, налоговые и другие льготы и поощрения, воздействие средств массовой коммуникации и разработанной системы этических правил и ценностей;

6) необходимо отметить, что согласующие воздействия органов власти на интересы стейкхолдеров в настоящее время существенно снижены и продолжают ослабляться в силу действия внешних и внутренних факторов объективного и субъективного плана, включая развитие глобализации, открытости отечественной экономики, демократизации управления, инновационных компьютерных технологий и их внедрение во все сфе- 
ры деятельности общества, укрепление частных капиталов и инвестиций, усиление транснациональных корпоративных образований. Влияние этих тенденций как имеет позитивные эффекты, так и обусловливает деструктивные изменения в промышленных системах, причем тем сильнее, чем менее развита экономика государства;

7) концептуально механизм менеджмента сбалансированности развития территориальных промышленных комплексов должен строиться, опираясь на следующую совокупность принципов:

а) приоритетность согласования целевых установок развития и функционирования промышленных комплексов территории в оперативном, тактическом и стратегическом аспекте;

б) опора на системный подход в решении задач менеджмента сбалансированности развития промышленности;

в) обеспечение гибкости механизма менеджмента сбалансированности развития территориальных промышленных комплексов, что определяется динамизмом делового окружения;

г) ориентация рассматриваемого механизма менеджмента на обеспечение промышленных комплексов всеми видами финансовых, материальных, природных, технико-технологических, социальных и других ресурсов в необходимом объеме и структуре;

д) повышение надежности прогнозирования показателей и тенденций развития промышленного комплекса и рыночной конъюнктуры;

е) внимание к системе социальной защиты населения;

ж) развитие конкурентных позиций промышленных компаний на своей территории;

3) согласование полномочий и ответственности стейкхолдеров на микро-, мезо- и макроуровнях управления индустриальным комплексом.

Как нам представляется, для реализации ряда предложенных принципов необходим стратегический анализ стейкхолдеров, который позволит выявить: совокупность стейкхолдеров внешнего окружения и внутренней среды, а также степень их влияния на ход развития компании; особенности экономических интересов стейкхолдеров и их соответствие целевым установкам промышленного комплекса; степень согласования приоритетных целей предприятий и их стейкхолдеров в ретроспективе; предвидение возможных позитивных и негативных вариантов изменений в деловых отношениях со стейкхолдерами (сценарии развития) и др.

На основе анализа теории и практики менеджмента сбалансированности развития необходимо выделить как наиболее результативные некоторые специальные инструменты для анализа и достижения согласованности интересов стейкхолдеров, к которым отнесем:

- карту заинтересованных сторон (Stakeholder's Map);

- таблицу интересов;

- $\quad$ матрицу «поддержка $\times$ сила влияния»;

- интегральную меру оценки окружения бизнеса [7, 8]

Указанные инструменты дают возможность оценивать и на этой основе поддерживать сбалансированность процессов функционирования промышленных комплексов при проведении в них преобразований, хотя они не всегда комплексно охватывают деятельность всех фирм и выделяют влияние основных стейкхолдеров на результаты развития индустрии, поэтому не могут осушествить преобразование отношений с внешней средой.

Заключение / Conclusion. Итак, для обеспечения комплексности в механизме менеджмента сбалансированности развития промышленных комплексов целесообразно шире использовать самоменеджмент [9] (самоконтроль и саморегулирование), который предполагает рост личной за- 
интересованности топ-менеджмента и ключевых сотрудников организации в согласовании приоритетов, целевых установок, запланированных результатов, на основе лучшего взаимопонимания и знания бизнес-процессов в рамках их компетенции.

В целях усиления влияния механизма менеджмента на уровень сбалансированности развития промышленных комплексов рекомендуем применение методов своевременного выявления и оперативного предупреждения бизнес-отклонений с долгосрочными последствиями, объединяя возможности оперативного управления и стратегического менеджмента.

Для объединения этих возможностей необходимо учесть, что механизмы управления развитием организации, инновациями, рисками обеспечиваются в основном в системе стратегического менеджмента, хотя они важны как в оперативном, так и в стратегическом аспекте. В каждой из подсистем менеджмента сбалансированности развития промышленных комплексов достижение целей осуществляется посредством реализации общих функций управления - планирования, организации, мотивации, контроля и анализа.

Критериально необходимой для управления сбалансированностью развития является подсистема инновационного менеджмента как на уровне компании, так и в рамках промышленного комплекса территории любого размера - это определяет возможность согласования изменений в перспективном плане. Скоординированные изменения должны происходить во всех подсистемах управления промышленными комплексами: в инвестировании, стратегическом маркетинге, мотивации работников, информационном обеспечении, - только тогда можно добиться желаемого уровня сбалансированности развития и обеспечить переход к новому технологическому укладу.

\section{ЛИТЕРАТУРА И ИНТЕРНЕТ-РЕСУРСЫ}

1. Freeman R. E. Strategic Management: A Stakeholder Approach. Boston, 1984.

2. Тимошенко П. Н. Категория сбалансированности в управлении промышленными предприятиями // Вестник Северо-Кавказского федерального университета. 2016. № 5.

3. Тимошенко П. Н., Ибрахим М. Современные информационно-аналитические инструменты в инноватике и управлении: коллективная монография. Ростов-н/Д.: ЮФУ, 2015.

4. Стратегические аспекты и целевые ориентиры управления инновационным развитием предприятий промышленности и транспорта региона в нестабильной социально-политической среде: коллективная монография / О. В. Година, С. В. Сажнева, Н. А. Ларионова и др. / под ред. профессора В. Н. Парахиной. Ставрополь: Изд-во СКФУ, 2015. 284 с.

5. Брянцева Л. В. Система сбалансированного управления промышленно-производственными подсистемами АГІК. Воронеж: Научная книга, 2009.

6. Парахина В. Н., Ханалиев Г. И. Концептуальные вопросы управления сбалансированным развитием регионов // Вестник Северо-Кавказского федерального университета. 2011. № 3. С. 244-249.

7. Воробьев И. Н. Управление развитием промышленных организаций на основе баланса целей и результатов [Электронный ресурс]. URL: http:/www.lerc.ru/?part=bulletin\&art $=53 \&$ page $=6$

8. Гончаров А. Ю., Сироткина Н. В. Сбалансированное региональное развитие. Стейколдеровский и социодарвинистский подходы // Регион: системы, экономика, управление. 2015. № 3 (30). С. 10-17.

9. Самоменеджмент: учебное пособие / В. Н. Парахина, В. И. Перов, О. А. Борис и др. под ред. В. Н. Парахиной, В. И. Перова. М.: Изд-во МГУ, 2012.

\section{REFERENCES AND INTERNET RESOURCES}

1. Freeman R. E. Strategic Management: A Stakeholder Approach. Boston, 1984.

2. Timoshenko P. N. Kategoriya sbalansirovannosti v upravlenii promyshlennymi predpriyatiyami (Category of balance in the management of industrial enterprises) // Vestnik Severo-Kavkazskogo federal'nogo universiteta. 2016. № 5.

3. Timoshenko P. N., Ibrakhim M. Sovremennyye informatsionno-analiticheskiye instrumenty v innovatike i upravlenii (Modern information and analytical tools in innovation and management): kollektivnaya monografiya. Rostov-n/D.: YUFU, 2015 
4. Strategicheskiye aspekty i tselevyye oriyentiry upravleniya innovatsionnym razvitiyem predpriyatiy promyshlennosti i transporta regiona v nestabil'noy sotsial'no-politicheskoy srede (Strategic aspects and targets of management of innovative development of enterprises of industry and transport in the region in an unstable socio-political environment): kollektivnaya monografiya / O. V. Godina, S. V. Sazhneva, N. A. Larionova i dr. / pod red. professora V. N. Parakhinoy. Stavropol': Izd-vo SKFU, 2015. 284 c.

5. Bryantseva L. V. Sistema sbalansirovannogo upravleniya promyshlenno-proizvodstvennymi podsistemami APK (The balanced management of industrial subsystems agroindustrial complex). Voronezh: Nauchnaya kniga, 2009.

6. Parakhina V. N., Khanaliyev G. I. Kontseptual'nyye voprosy upravleniya sbalansirovannym razvitiyem regionov (Conceptual issues of balanced regional development management) // Vestnik SeveroKavkazskogo federal'nogo universiteta. 2011. № 3. S. 244-249.

7. Vorob'yev I. N. Upravleniye razvitiyem promyshlennykh organizatsiy na osnove balansa tseley i rezul'tatov [Elektronnyy resurs] URL: http://www.lerc.ru/?part=bulletin\&art $=53$ \&page $=6$

8. Goncharov A. YU., Sirotkina N. V. Sbalansirovannoye regional'noye razvitiye. Steykolderovskiy i sotsiodarvinistskiy podkhody // Region: sistemy, ekonomika, upravleniye. 2015. № 3 (30). S. 10-17.

9. Samomenedzhment: uchebnoye posobiye / V. N. Parakhina, V. I. Perov, O. A. Boris i dr. pod red. V. N. Parakhinoy, V. I. Perova. M.: Izd-vo MGU, 2012.

\section{СВЕДЕНИЯ ОБ АВТОРЕ}

Тимоменко Павел Николаевич, кандидат экономических наук, доцент, заведующий кафедрой гуманитарных дисциплин, Невинномысский государственный гуманитарно-технический институт. E-mail: timpol@bk.ru

\section{INFORMATION ABOUT AUTHOR}

Pavel Timoshenko, Candidate of Economic Sciences, Associate Professor, Head of the Department of Humanitarian Disciplines, Nevinnomy ssk State Humanitarian-Technical Institute. E-mail: timpol@bk.ru 